\title{
High viremia and low level of transmitted drug resistance in anti-retroviral therapy-naïve perinatally-infected children and adolescents with HIV-1 subtype $C$ infection
}

\author{
Ujjwal Neogi ${ }^{1,2}$, Pravat Nalini Sahoo ${ }^{2}$, Ayesha De Costa ${ }^{3}$ and Anita Shet ${ }^{3,4^{*}}$
}

\begin{abstract}
Background: High plasma viremia in HIV-1 infection is associated with rapid CD4 cell decline and faster disease progression. Children with HIV infection have high viral loads, particularly in early childhood. In this study we sought to understand the relationship between duration of HIV-1 infection and viral dynamics among perinatally-infected children and adolescents in India along with transmitted drug resistance in this population.

Methods: During 2007-2011, cross-sectional samples were collected from ART-naïve children $(n=105)$ with perinatally-acquired HIV infection, aged 2-16 years from Bangalore, India. CD4 counts, viral load and in-house genotyping were performed and transmitted drug resistance mutations were identified using the World Health Organization recommendations for Surveillance of Drug Resistance Mutations (SDRM_2009) list.

Results: Among 105 children studied, 73.3\% (77/105) were asymptomatic, but had a median viral load of 5.24 log copies/mL (IQR 4.62-5.66). In the adolescent age group, 54\% (21/39) had high levels of viremia (median 5.14 log copies $/ \mathrm{mL}$ ) but were asymptomatic. HIV-1 subtyping identified $98 \%$ strains (103/105) as subtype C; one A1 and one unique recombinant form (URF). Transmitted NRTI resistance was 1.9\% (2/105); NNRTI resistance was 4.8\% (5/105) and overall prevalence of transmitted drug resistance was 5.7\% (6/105).

Conclusions: The high burden of plasma viremia found among untreated asymptomatic adolescents needs to be addressed both from an individual angle to halt disease progression, and from a public health perspective to arrest horizontal transmission. The low level of transmitted drug resistance among perinatally-infected children is reassuring; however with improving ART access globally, regular genotyping surveillance is indicated.
\end{abstract}

Keywords: HIV-1 perinatal transmission, Subtype C, Viral dynamics, India

\section{Background}

Globally, 3.4 million children below 15 years of age are living with HIV as of 2010 (World Health Organisation, Global summary of the AIDS epidemic, 2010). Among them 1.4 million children reside in the South-east Asia region alone. India has a burden of nearly 2.5 million HIV-1 infected individuals, with children below 15 years of age constituting $3.5 \%$ of the total number [1].

\footnotetext{
* Correspondence: anitashet@gmail.com

${ }^{3}$ Division of Global Health, Karolinska Institutet, Stockholm, Sweden ${ }^{4}$ Department of Paediatrics, St. John's National Academy of Health Sciences, Bangalore 560034, India

Full list of author information is available at the end of the article
}

Viral load dynamics occurring immediately after infection has been well characterized in adults [2]. Perinatal infection has differing post-transmission dynamics, and consists of a rapid rise in the viral load up to $10^{5}$ to $10^{7}$ copies/ $\mathrm{ml}$ during the first weeks of life followed by a declining trend up to 5 to 6 years [3-5]. Extracellular viral load is a strong indicator of viral replication and high viremia is associated with high transmissibility of HIV-1 [6-8]. Although HIV-1 subtype C infection accounts for nearly half $(48 \%)$ of global HIV infections, few studies have focussed on subtype $\mathrm{C}$ viral dynamics. High viremia is seen in a substantial proportion of adults with HIV-1 subtype $\mathrm{C}$ infection acquired via horizontal transmission 
$[8,9]$. Specific data on viral dynamics among perinatallyinfected children are limited [3] and have not been studied within the context of HIV-1 subtype $\mathrm{C}$ infection.

Transmitted drug resistance mutation (TDRM) surveillance in children can help to enhance our understanding of transmission of specific clinically-relevant mutations in the era of rapid scale-up of free antiretroviral therapy, particularly prevention of mother-to-child transmission measures. In India, although few studies have previously addressed prevalence of TDRM in adults, [10-12] limited information is available for children and adolescents. The present study aims to understand the relationship between the duration of HIV-1 infection and viremia in children in a setting of HIV-1 subtype $\mathrm{C}$ dominance. In addition, the study reports the prevalence of transmitted drug resistant mutations among ART-naive perinatally-infected children.

\section{Methods}

\section{Study population}

The study participants included all children with HIV-1 infection who were regularly visiting the Infectious Disease Clinic at a tertiary care hospital, St. John's Medical College and Hospital, Bangalore, India since March 2007. Among these, 105 children aged between 2 to 16 years who were perinatally infected, ART-naïve, and with no antenatal exposure to ART, were included in this analysis.

Perinatal infection was confirmed by documented evidence that the mother or both parents were HIVinfected. There was no history of blood transfusion, cross-breast feeding or sexual abuse/exposure among the children included in the study. All the children were therapy-naïve and were diagnosed in early or middle childhood at an average age of 6 years. Maternal HIV status was unknown at the time of birth of these children but was confirmed subsequently, and none of the mothers had received prophylactic antiretroviral drugs during the antenatal period.

\section{Viral Load, PCR and sequencing}

Between 2007 and 2011, a single peripheral blood sample was obtained from each study subject during a routine follow up visit in the clinic. Given that the children in the study were confirmed to be perinatally infected, the duration of HIV infection at the time of sample draw in these children was known. Plasma was separated out after centrifugation and stored at $-80{ }^{\circ} \mathrm{C}$ until used. Viral load was measured by real time polymerase chain reaction using the Abbott m2000rt system (Abbott Molecular Diagnostics, Germany). Routine CD4 count was measured with Dual-platform flow cytometer (FACS Calibur, BD, USA). PCR and sequencing was carried out as described by us previously [10]. In brief, viral RNA was extracted from plasma using a commercial kit (QIAamp Viral RNA extraction kit, Qiagen, Germany). Partial RT, HXB2 position 2598 to 3250 (corresponds to 17-235 amino acid) regions of the polymerase (pol) gene were amplified using reverse transcriptase polymerase chain reactions (RT-PCR) followed by conventional nested PCR using the following primers, RT04 5'-CCTATTGAAACTGTACCAGT-3' and RT05,5'-AC TGTCCATTTATCAGGATG-3' followed by RT07 $5^{\prime}$ AAGCCAGGAATGGATGGCCCA-3' and RT06 5'-CC ATTTATCAGGATGGAGTTC- $3^{\prime}$. The purified PCR products were subjected to bidirectional population sequencing using RT06 and RT07 primers in 3730xl DNA analyzer (Applied Biosystems, CA, USA) using the second round primers. A consensus sequence was created using BioEdit sequence alignment editor version 7.0.5.3 [13].

\section{Quality control}

An external quality control program by the Quality Control for Molecular Diagnostics, Glasgow, Scotland (QCMD, www.qcmd.gov) was maintained by the laboratory where these analyses were performed.

\section{Reference sequences}

Reference sequences (2010) of different subtypes ( $\mathrm{n}=170)$ were downloaded from HIV-1 Los Alamos Database ("LANL", www.hiv.lanl.gov). The reverse transcriptase (RT) sequences of previously reported sequences from India, obtained from patients where the therapy status was documented, were downloaded from the same database. A total 595 RT sequences from therapy-naïve patients were downloaded from the LANL database reported in previous studies from India [10-12,14-19]. The downloaded sequences were assessed for accuracy by using the Los Alamos Quality Control tool (LANL_QC) for HIV-1 sequences. Using this tool, sequences with frame shifts, $\geq 3$ stop codons, and APOBEC-mediated hypermutations were excluded, leaving the remaining 567 unique and correctly aligned sequences for the final analysis.

\section{Phylogenetic analysis, subtyping and recombinant screening}

Subtyping was inferred using a maximum likelihood (ML) phylogenetic tree constructed with 1000 bootstrapped data sets, using the Molecular Evolutionary Genetics Analysis software version 5 (MEGA 5) with the subtype reference sequences downloaded from the database [20]. All sequences were further submitted to Recombination Identification Program 3.0 (RIP 3.0). The sequences which showed recombination were further processed for detailed analysis of recombination breakpoints. Recombination patterns were determined by performing bootscan analysis with Simplot version 3.5.1 
[21], using a window sliding of 100 nucleotide (nt) in 10nt steps, with 500 bootstrap replicates. The mosaic pattern of each URF was confirmed by phylogenetic analysis of the recombination fragments using the same parameters as described above.

\section{Drug resistance genotyping and definition of transmitted drug resistance mutations}

Genotyping was performed on plasma samples derived from ART-naïve children. Briefly, the reverse transcriptase (RT) region of HIV-1 pol gene was amplified and sequenced using the primers described above. These sequences were analysed for the presence of transmitted drug resistance using the World Health Organization (WHO) recommendations for surveillance of drug resistance mutations updated in 2009 (SDRM_2009) [22]. This list includes 34 NRTI-resistance mutations at 15 RT positions, and 19 NNRTI-resistance mutations at $10 \mathrm{RT}$ positions [22]. We also used the International AIDS Society-USA updated drug resistance mutations in HIV-1 (IAS-USA 2011) for interpretation of TDRM. IAS-USA 2011 includes 19 NRTI mutations in 16 positions, and 34 NNRTI mutations in 16 positions between amino acid residues 17 to 235 of RT region of pol [23]. To further increase the accuracy of this analyses, we eliminated certain mutations included in the SDRM_2009 or IAS Panel, which displayed characteristics of polymorphisms (defined as those mutations which are normally present at a frequency of $\geq 0.5 \%$ in therapy-naïve patients, and at a frequency of $<0.5 \%$ among those failing therapy) [22].

\section{Intra-population divergence}

The genetic distance of each of the study sequences to the Indian consensus $\mathrm{C}$ sequence (intra-population divergence) was calculated in MEGA 5 software [20].

\section{Statistical methods}

Descriptive statistics like mean, median were calculated in SPSS ver 16.0. A spearman rank co-relation $\left(r_{s}\right)$ was used for analysis of potential co-relation between continuous variables. $P$ value $<0.05$ was considered as significant.

\section{Ethical statement}

The study has been approved by institutional ethical review board, St. John's Medical College Hospital, Bangalore, India. Written informed consent was obtained from all caregivers prior to recruitment of the children, and a verbal assent was obtained from children $>8$ years of age.

\section{Results}

\section{Study population characteristics}

Among the total of 105 children studied, mean age was 8 years $(\mathrm{SD} \pm 3.4)$ and median CD4 count was 530 cells/ $\mathrm{mm}^{3}$ (IQR 338, 780) (Table 1). Median viral load was $5.24 \log$ copies/mL (IQR 4.62, 5.66) and $73.3 \%$ of these children (77/105) were classified as clinically stable (WHO clinical stage I or II) and remaining 28 children were classified as symptomatic (WHO clinical stage III or IV). As perinatal infection was the most likely mode of transmission, the duration of infection was deemed to be equivalent to the age of each child.

\section{Extended high viremia and CD4 count}

Viral load values remained similar regardless of age, and showed no significant correlation with duration of infection in these populations (Figure 1). CD4 T-cell count weakly correlated with viral load among children $\geq 5$ years of age $(n=88$; Spearman rho $=-0.26)$. Among these 88 children, 58\% (51/88) were extended high viremics $(>5.0$ $\log$ copies $/ \mathrm{mL}$ as described previously [8]) and among these, 67\% (34/51) had CD4 count higher than 350 cells/ $\mathrm{mm}^{3}$. In the adolescent age group (10-16 years of age, $\mathrm{n}=39), 54 \%(21 / 39)$ had extended high viremia (median 5.14 log copies/mL; IQR 4.69-5.34) despite having a CD4 T-cell counts $>350$ cells $/ \mathrm{mm}^{3}$.

\section{HIV-1 subtyping}

HIV-1 subtyping based on RT region of pol gene (HXB2 position 2598 to 3250$)$ identified 98\% strains (103/105) as subtype $C$ which is predominant in India [24] (Figure 2). One sample was identified as subtype A1 and one as a unique recombinant form $\mathrm{CH}$ (URF_CH). (Figure 3).

\section{Transmitted drug resistance and polymorphisms}

Using the SDRM_2009 list [22] for drug resistance monitoring, we found that among the 105 ART-naive children, 3.8\% (4/105) had transmitted NRTI drug resistance mutations (L74I, T69D, T215S and K219Q) and $4.8 \%(5 / 105)$ had NNRTI drug resistance mutations [K103N $(\mathrm{n}=2), \operatorname{K101E}(\mathrm{n}=2), \mathrm{Y} 181 \mathrm{C}(\mathrm{n}=1)]$. After excluding likely polymorphisms such as L74I and T215S, transmitted NRTI resistance prevalence was $1.9 \%(2 / 105)$. The overall prevalence of transmitted drug resistance in this population was $5.7 \%(6 / 105)$. Among the six strains, only one had two classes of mutations (both NRTI and NNRTI) (Table 2).

When the IAS-USA 2011 list [23] was used for TDRM interpretation, a slightly differing result was obtained. The NRTI resistance prevalence was $0.9 \% \quad(1 / 105$; K219Q) and NNRTI resistance was 5.7\% [6/105; K103N $(\mathrm{n}=2), \mathrm{K} 101 \mathrm{E}(\mathrm{n}=2), \mathrm{Y} 181 \mathrm{C}(\mathrm{n}=1), \mathrm{F} 227 \mathrm{C}(\mathrm{n}=1)]$. But the overall transmitted drug resistance prevalence remained the same; $5.7 \%(6 / 105)$. 
Table 1 Patient demography and clinical status of the study participants

\begin{tabular}{|c|c|c|c|c|}
\hline & $\begin{array}{l}\text { Over all } \\
(n=105)\end{array}$ & $\begin{array}{l}<5 \text { years } \\
(n=17)\end{array}$ & $\begin{array}{c}\geq 5 \text { to }<10 \text { years } \\
(n=49)\end{array}$ & $\begin{array}{c}\geq 10 \text { years } \\
(n=39)\end{array}$ \\
\hline Sex: Male (\%) & $61(58.1 \%)$ & $12(70 \%)$ & $29(59 \%)$ & $20(51 \%)$ \\
\hline CD4-T cell count & $530(338-780)$ & $1051(528-1154)$ & $586(401-768)$ & $373(251-578)$ \\
\hline \multicolumn{5}{|l|}{ Median $\left(\mathrm{IQR}^{*}\right)$} \\
\hline Viral load log copies/mL & $5.24(4.62-5.66)$ & $5.56(5.51-6.05)$ & $5.12(4.55-5.55)$ & $5.2(4.73-5.63)$ \\
\hline \multicolumn{5}{|l|}{ Median $\left(\mathrm{IQR}^{*}\right)$} \\
\hline \multicolumn{5}{|l|}{ WHO Clinical stage } \\
\hline Stage 1 & $40(38.1 \%)$ & $6(35.3 \%)$ & 19 (38.7\%) & $15(38.5 \%)$ \\
\hline Stage 2 & $37(35.2 \%)$ & $5(29.4 \%)$ & 19 (38.7\%) & $13(33.3 \%)$ \\
\hline Stage 3 & $22(21 \%)$ & $4(23.5 \%)$ & $9(18.4 \%)$ & $9(23.1 \%)$ \\
\hline Stage 4 & $6(5.7 \%)$ & $2(11.8 \%)$ & $02(4.1 \%)$ & $2(5.1 \%)$ \\
\hline
\end{tabular}

*IQR: Inter-quartile range.

The profiles of children with transmitted drug resistance are presented in Table 2. Children who had TDRM $(n=6)$, had higher mean viral load compared to those with no TDRM $(\mathrm{n}=99)(5.75$ vs $5.16 \log$ copies $/ \mathrm{mL} ; \mathrm{p}=$ 0.06 ) although only a trend towards significance was seen due to the small sample size. Among the six children who had TDRM, 3 children had severe immunosuppression and were deemed eligible to start ART.

\section{Discussion}

Our study on viral dynamics and drug resistance testing among ART-naive perinatally-infected children aged between 2 and 16 years found that a substantial proportion of older children with CD4 T cell count in the 'nonimmunosuppressed' category had high viremia. As expected subtype $\mathrm{C}$ is the most prevalent HIV-1 subtype in this study population. We also identified a low level of transmitted drug resistance in this population.

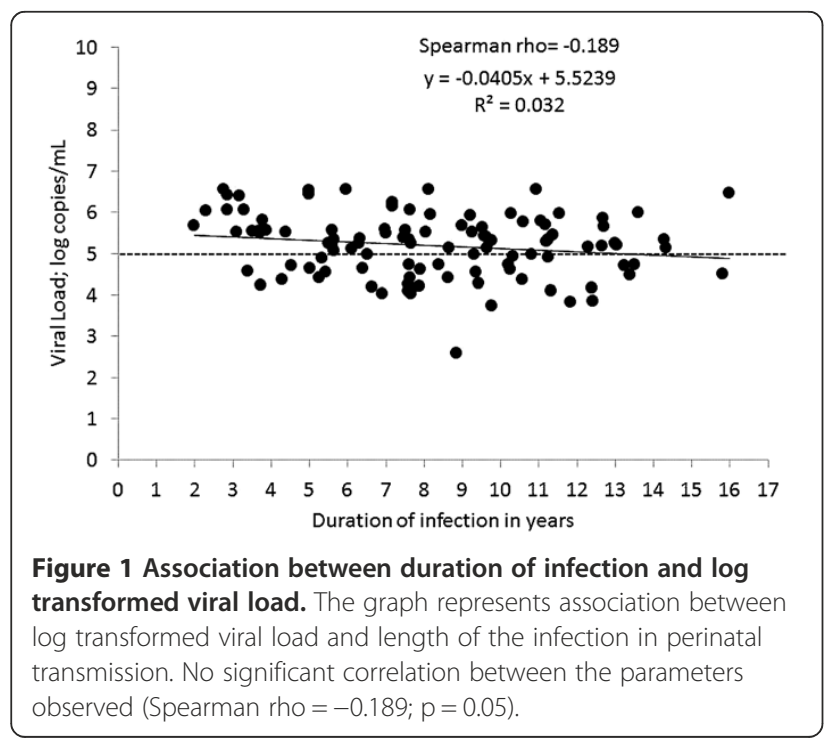

A recent study showed that a proportion of HIVinfected adults with horizontally-acquired subtype $\mathrm{C}$ infection in southern Africa maintained high viral loads for a prolonged period of time [8]. A South African cohort of HIV-1-infected infants also demonstrated high viral load where HIV-1 subtype C is predominant [25]. A comparative study between Malawi and US/Swiss study participants also showed a significant higher viral load in Malawians, suggesting the possibility that high viremia may occur more frequently in subtype $C$ rather than subtype B infection [9]. In our cohort, the duration of infection as measured by the age of these children, did not directly correlate with the degree of viremia, thus precluding viral load measurement as a prognostic marker of disease length; moreover, there was a substantial proportion of adolescents who maintained high CD4 T-cell count but had elevated viremia as well. Our findings imply that even in vertical transmission, a proportion of HIV-1 subtype C-infected children and adolescents have high viremia irrespective of their stable clinical and immunological status. To minimize horizontal transmission among youth, targeted interventions with treatment as prevention among adolescents with high viremia may be of public health benefit which could also be a cost-effective strategy to attain maximum population-level reductions in HIV-1 transmission [26].

The transmitted drug resistance prevalence was derived by using the SDRM 2009 list [22]. The SDRM 2009 list was compiled keeping in mind four main concepts: (i) included mutations should be recognized as causing or contributing to drug resistance - by being present on $\geq 3$ of five existing expert lists of drug resistance mutations, namely, Stanford university HIVdb drug resistance interpretation algorithm (http://hivdb. stanford.edu/). IAS-USA Mutations Associated With Drug Resistance (March/April 2008), ANRS drug resistance interpretation algorithm, Los Alamos National 


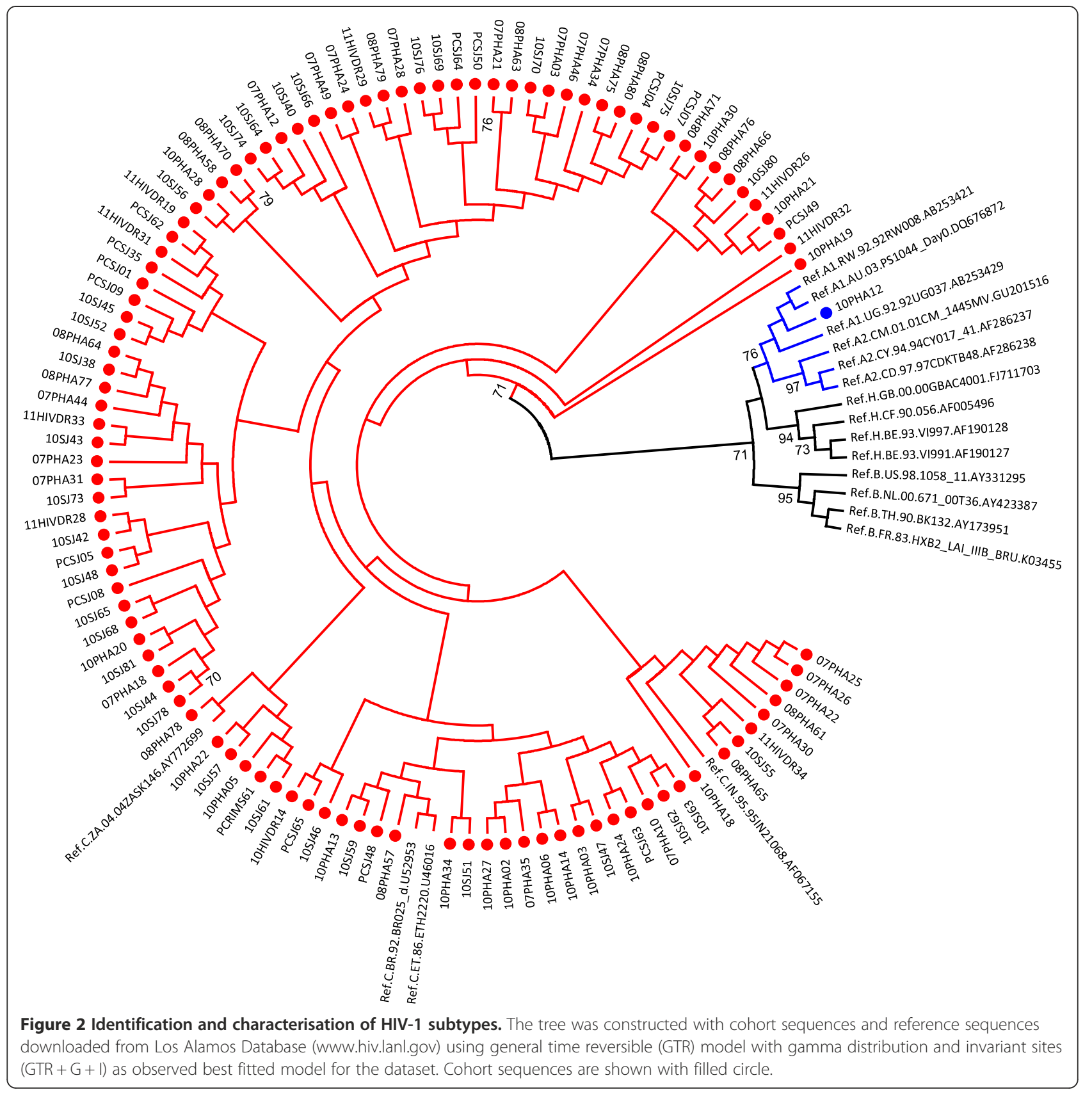

Laboratories HIV Sequence database (2007), or Rega Institute Drug Resistance Interpretation Algorithm (7.1.1) (ii) the mutations should not be polymorphisms or occur at highly polymorphic positions, (iii) the mutations should be applicable to the 8 most common HIV-1 subtypes globally and (iv) the list should be parsimonious, excluding mutations that are unlikely to result from drug pressure. These criteria have shaped the SDRM 2009 list to be especially relevant in our setting, and hence this list was used for our current interpretation. The TDRM level in our study population was very low which was consistent with our previous findings where the level of
TDRMS and polymorphisms among ART-naïve adults did not exceed 10\% [10]. Other paediatric studies from India have revealed similar low TDRM prevalence; among a south Indian cohort of 48 perinatally infected children of mean age 5.7 years, none had major drug resistance mutations [27]. In another study from north India where 25 ART-naive children with mean age 6 years were studied, K103N was the only drug resistance mutation that was observed [28]. Studies on ARTnaïve adults from different parts of India with sample sizes ranging from 34 to 107 patients, have revealed low TDRM prevalence $(<5 \%)[11,12,14-18]$. 


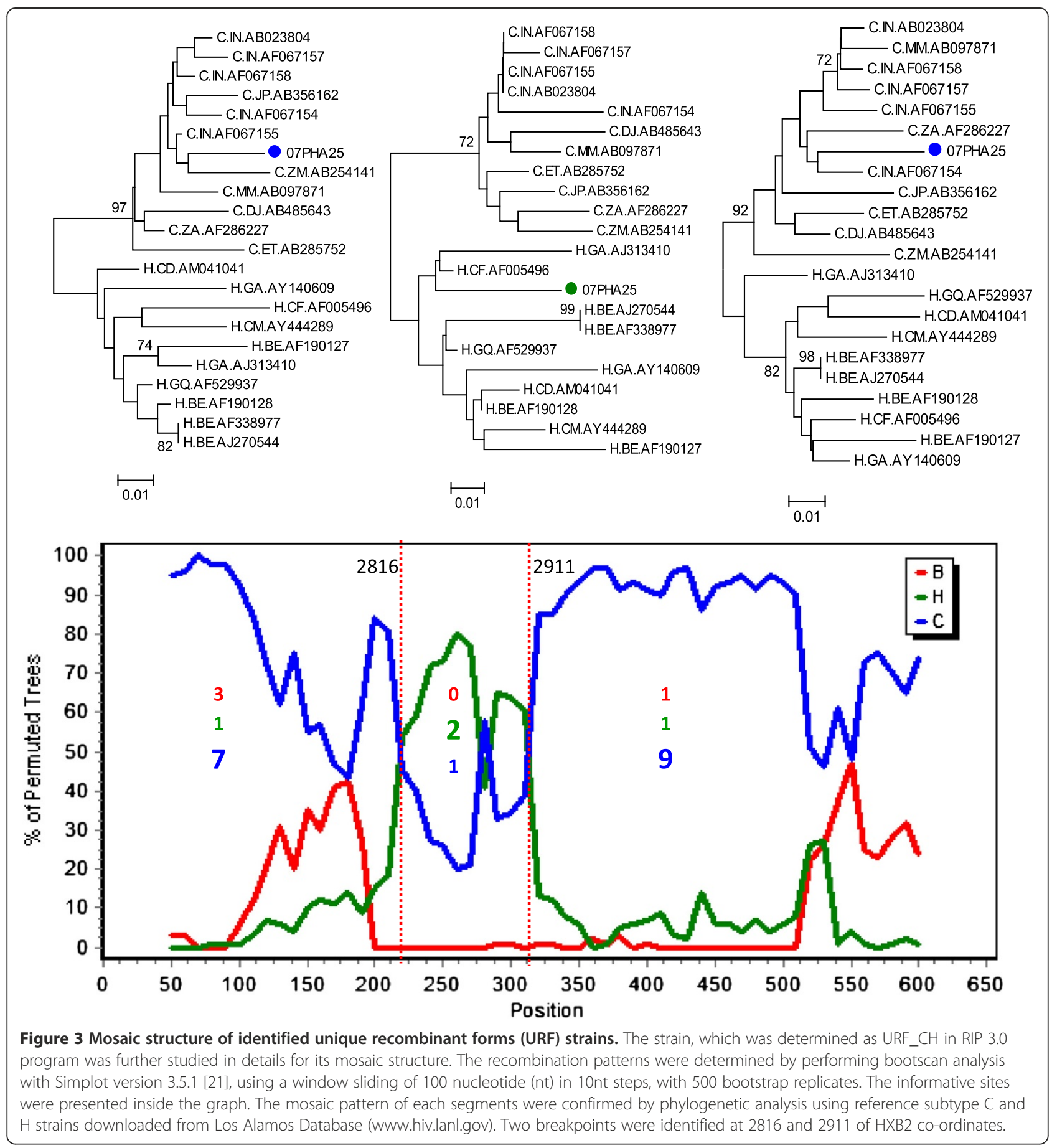

Table 2 Profile of children with transmitted drug resistance

\begin{tabular}{|c|c|c|c|c|c|c|}
\hline Patient No & Length of infection (years) & WHO Stage & CD4 Count (cells $/ \mathrm{mm}^{3}$ ) & Viral Load (log copies/mL) & NRTI SDRMs & NNRTI SDRMs \\
\hline 1 & 16 & 3 & 221 & 6.46 & None & K103N \\
\hline 2 & 11 & 3 & 417 & 5.34 & None & K101E \\
\hline 3 & 11 & 4 & 14 & 5.69 & T69D & None \\
\hline 4 & 9 & 1 & 247 & 5.08 & None & K103N \\
\hline 5 & 9 & 1 & 401 & 5.50 & K219Q & K101E \\
\hline 6 & 6 & 2 & 288 & 6.55 & None & Y181C \\
\hline
\end{tabular}


Presence of K103N and K101E TDRM in our cohort sequences may be due to wide usage of nevirapine in this setting [29]. Our data on prevalence of TDRM among children was significantly lower than other settings. Studies from Brazil reported 26.9\% of TDRM in therapy-naïve children [30], while a report from Central African Republic identified 13.9\% [31]. A meta-analysis showed that approximately half of the children with PMTCT exposure (single-dose nevirapine) harboured TDRM [32]. A recent study from Spain on PMTCTexposed children identified 13\% TDR [33], while another study from Western Cape Province of South Africa reported TDRM $<5 \%$ among children who were exposed to PMTCT [34]. A recent study also showed that the effect of viral fitness on HIV RNA level could be one of the determining factors for selective viral transmission; maternal presence of mutations such as $\mathrm{K} 103 \mathrm{~N}$ which promote viral fitness may be easily transmitted to infants [35].

Minor differences between the two lists used for TDRM interpretation can lead to contradictory prevalence results of drug resistance. In our study, we excluded minor NRTI mutations such as T215S and L74I which were included in the SDRM 2009 list. The SDRM 2009 WHO group recommends that the SDRM list should be "as parsimonious as possible without sacrificing sensitivity," this can be accomplished by excluding "exceedingly rare drug-resistance mutations defined as those mutations present at a frequency below $0.5 \%$ among treated individuals in the subtype having the highest prevalence of that mutation" [22]. Our analysis of previous RT sequences obtained from treatmentexperienced patients from Indian subtype $C$ patients $[n=$ 606; downloaded from the Los Alamos database $(\mathrm{n}=$ 102); literature survey $(\mathrm{n}=446)$ and unpublished from lab $(\mathrm{n}=58)$ ] revealed that T215S was not present in any of the sequences (data not shown). Although in vitro analysis showed that T215S represents revertants of T215Y [36], phenotypic characterisation did not show resistance to any nucleoside analogues including zidovudine [37]. The L74I mutation was present in $0.3 \%(2 / 606)$ of sequences obtained from treatment-experienced patients infected with subtype $C$ viruses. In addition, the analysis of global subtype C sequences in HIVseq program available in Stanford University HIV drug resistance database (http://hivdb.stanford.edu/; accessed 07 October 2012) also revealed absence of both mutations in 232 HIV-1 subtype $\mathrm{C}$ sequences from NRTI-treated patients. The low prevalence of T215S and L74I at a frequency of $<0.5 \%$ in treatment-experienced patients harbouring subtype C HIV-1 provided the basis for our rationale for excluding these mutations from our analysis. F227C is another example of a mutation included in the IAS-USA panel that is not likely to be significant as a transmitted mutation, as F227C confers "minor" resistance to rilpivirine, a drug that is as yet unavailable in India. Other studies have observed differences in prevalence of TDRM within the same cohort when differing tools such as SDRM 2009 and IAS-USA 2009 are used [38]. Current SDRM 2009 guidelines propose that such polymorphic drug resistance mutations which occur commonly in the absence of drug selective pressure, and are present in $<0.5 \%$ of the treated population, could lead to falsely elevated estimates of TDRM, and hence, must not be included for surveillance of transmitted HIVDR [22].

Our study limitations include the cross-sectional design which restricts our ability to comment on kinetics of viral dynamics and evolution. Further, we have not been able to include samples from children below two years of age for this analysis as most of the children in our settings were diagnosed in their early and middle childhood. There may be an inherent survival bias since only these older children were included in the study. Thus, having only chronically infected children may actually underestimate the prevalence of transmitted drug resistance as the wild type virus with increased fitness may predominate and minor viral populations with drug resistant mutations may be too low to detect using population sequencing. However, our study is strengthened by the inclusion of a high proportion of children with age $\geq 10$ years, which allowed us to study viral load and its associations in adolescents. Finally, the population-based genotyping method can only detect mutations that are present in $30 \%$ or more of the quasi-species constituting circulating virus population [39]. It is possible that mutations carried by minor viral populations may be missed due to the limited sensitivity of population-based sequencing method.

\section{Conclusions}

Our study is the first of its kind which describes the relationship between the length of infection and the degree of viremia in perinatally-infected children and adolescents living with HIV-1 subtype $\mathrm{C}$ in India. A significant finding of this study is the inconsistent clinical parameters of high viral load and high CD4 count co-existing in over half the adolescents studied, where the duration of infection is $>10$ years. Studies have shown a high probability of disease progression to AIDS among those with high viremia [40]. Will this group of adolescent extended high viremics experience imminent rapid disease progression as has been seen in adult studies? It is conceivable that extended high viremia with drug resistance mutations in untreated adolescents may also play a role in fuelling the HIV epidemic. Therefore, early initiations of ART while emphasizing good adherence may be considered in this population in order to attain maximum population-level 
reductions in HIV-1 transmission. The evidence from this study also suggests that the interpretation of prevalence of TDRM in population-based surveillance should be used with caution to avoid reporting falsely elevated TDR prevalence in the population. The low level of transmitted drug resistance in children unexposed to antenatal antiretroviral drugs, although reassuring, should not advocate complacency. Regular surveillance is necessary to understand the evolution of drug resistance mutations, particularly with increasing PMTCT coverage nationally and globally.

\section{Competing interests}

The authors declare that they have no competing interests.

\section{Authors' contributions}

UN conceived of the study, and participated in its design, carried out the drug resistance genotyping, bioinformatics analysis, performed the statistical analysis and drafted the manuscript. PNS carried out the lab works, helped in clinical data accumulations. ADC performed the statistical analysis, inputs in the public health aspects and critically reviewed the manuscript. AS conceived of the study, and participated in its design and critically reviewed the manuscript. All authors read and approved the final manuscript.

\section{Acknowledgements}

We thank the staff of the Pediatric Infectious Disease Clinic, St. John's Hospital, Bangalore, and Sneha Care Home for assistance with patient recruitment. A special thanks to Shwetha D Rao, for helping in the data collection. We would also like to thank the National AIDS Control Organisation (NACO), Government of India, for their support and care of these children. Most importantly, we are ever grateful to the children for participating in this study and giving so much to help us learn.

\section{Funding}

The study was partly funded by the Child Health Foundation, the International Nutrition Foundation, the Indian Council of Medical Research, and the European Union FP7 grant.

\section{Author details}

'Division of Infectious Disease, Department of Medicine, Huddinge, Karolinska Institutet, Stockholm, Sweden. ${ }^{2}$ Division of Clinical Virology, Department of Microbiology, St. John's National Academy of Health Sciences, Bangalore, India. ${ }^{3}$ Division of Global Health, Karolinska Institutet, Stockholm, Sweden. ${ }^{4}$ Department of Paediatrics, St. John's National Academy of Health Sciences, Bangalore 560034, India.

Received: 6 June 2012 Accepted: 20 November 2012

Published: 22 November 2012

\section{References}

1. National AIDS Control Organization, Annual Report, 2009-2010. http:// nacoonline.org/upload/AR\%202009-10/NACO_AR_English\%20corrected.pdf.

2. Shankarappa R, Margolick JB, Gange SJ, Rodrigo AG, Upchurch D, Farzadegan H, Gupta P, Rinaldo CR, Learn GH, He X, Huang XL, Mullins Jl: Consistent viral evolutionary changes associated with the progression of human immunodeficiency virus type 1 infection. J Virol 1999, 73:10489-10502.

3. Ganeshan S, Dickover RE, Korber BT, Bryson YJ, Wolinsky SM: Human immunodeficiency virus type 1 genetic evolution in children with different rates of development of disease. J Virol 1997, 71:663-677.

4. McIntosh K, Shevitz A, Zaknun D, Kornegay J, Chatis P, Karthas N, Burchett SK: Age- and time-related changes in extracellular viral load in children vertically infected by human immunodeficiency virus. Pediatr Infect Dis $J$ 1996, 15:1087-1091.

5. Shearer WT, Quinn TC, LaRussa P, Lew JF, Mofenson L, Almy S, Rich K, Handelsman E, Diaz C, Pagano M, Smeriglio V, Kalish LA: Viral load and disease progression in infants infected with human immunodeficiency virus type 1. Women and Infants Transmission Study Group. N Engl J Med 1997, 336:1337-1342.

6. Quinn TC, Wawer MJ, Sewankambo N, Serwadda D, Li C, Wabwire-Mangen F, Meehan MO, Lutalo T, Gray RH: Viral load and heterosexual transmission of human immunodeficiency virus type 1. Rakai Project Study Group. N Engl I Med 2000, 342:921-929.

7. Modjarrad K, Chamot E, Vermund SH: Impact of small reductions in plasma HIV RNA levels on the risk of heterosexual transmission and disease progression. AIDS 2008, 22:2179-2185.

8. Novitsky V, Ndung'U T, Wang R, Bussmann H, Chonco F, Makhema J, DeGruttola V, Walker BD, Essex M: Extended high viremics: a substantial fraction of individuals maintain high plasma viral RNA levels after acute HIV-1 subtype C infection. AIDS 2011, 25:1515-1522.

9. Dyer JR, Kazembe P, Vernazza PL, Gilliam BL, Maida M, Zimba D, Hoffman IF, Royce RA, Schock JL, Fiscus SA, Cohen MS, Eron JJ Jr: High levels of human immunodeficiency virus type 1 in blood and semen of seropositive men in sub-Saharan Africa. J Infect Dis 1998, 177:1742-1746.

10. Neogi U, Prarthana BS, Gupta S, D'souza G, De Costa A, Kuttiatt VS, Arumugam K, Shet A: Naturally occurring polymorphisms and primary drug resistance profile among antiretroviral-naïve individuals in Bangalore, India. AIDS Res Hum Retroviruses 2010, 26:1097-1101.

11. Thorat SR, Chaturbhuj DN, Hingankar NK, Chandrasekhar V, Koppada R, Datkar SR, Srikantiah P, Garg R, Kabra S, Haldar P, Reddy DC, Bachani D, Tripathy SP, Paranjape RS: Surveillance of transmitted HIV type 1 drug resistance among HIV type 1-positive women attending an antenatal clinic in Kakinada, India. AIDS Res Hum Retroviruses 2011, 27:1291-1297.

12. Chaturbhuj DN, Hingankar NK, Srikantiah P, Garg R, Kabra S, Deshmukh PS, Jadhav SD, Thorat SR, Datkar SR, Mehta P, Ingole N, Mathur M Ramachandran A, Haldar P, Reddy DC, Bachani D, Rao S, Tripathy SP, Paranjape RS: Transmitted HIV drug resistance among HIV-infected voluntary counselling and testing centers (VCTC) clients in Mumbai, India. AIDS Res Hum Retroviruses 2010, 26:927-932.

13. Hall TA: BioEdit: A user-friendly biological sequence alignment editor and analysis program for Windows 95/98/NT. Nucl Acids Symp Ser 1999, 41:95-98.

14. Sinha S, Ahmad H, Shekhar RC, Kumar N, Dar L, Samantaray JC, Sharma SK, Bhargava A, Pandey RM, Mitsuyasu RL, Fahey JL: Prevalence of HIV drug resistance mutations in HIV type 1 isolates in antiretroviral therapy naïve population from northern India. AIDS Res Treat 2012, 2012:905823.

15. Deshpande A, Karki S, Recordon-Pinson P, Flury HJ: Drug resistance mutations in HIV type 1 isolates from naive patients eligible for first line antiretroviral therapy in JJ Hospital, Mumbai, India. AIDS Res Hum Retroviruses 2011, 27:1345-1347.

16. Iqbal HS, Solomon SS, Madhavan V, Solomon S, Balakrishnan P: Primary HIV-1 drug resistance and polymorphic patterns among injecting drug users (IDUs) in Chennai, Southern India. J Int Assoc Physicians AIDS Care (Chic) 2009, 8:323-327.

17. Rajesh L, Karunaianantham R, Narayanan PR, Swaminathan S: Antiretroviral drug-resistant mutations at baseline and at time of failure of antiretroviral therapy in HIV type 1-coinfected TB patients. AIDS Res Hum Retroviruses 2009, 25:1179-1185.

18. Kandathil AJ, Kannangai R, Abraham OC, Rupali P, Pulimood SA, Verghese VP, Grant P, Pillay D, Sridharan G: The frequency of HIV-I drug resistance mutations among treatment-naive individuals at a tertiary care centre in south India. Int J STD AIDS 2009, 20:522-526.

19. Balakrishnan P, Kumarasamy N, Kantor R, Solomon S, Vidya S, Mayer KH, Newstein M, Thyagarajan SP, Katzenstein D, Ramratnam B: HIV type 1 genotypic variation in an antiretroviral treatment-naive population in southern India. AIDS Res Hum Retroviruses 2005, 21:301-305.

20. Tamura K, Peterson D, Peterson N, Stecher G, Nei M, Kumar S: MEGA5: Molecular Evolutionary Genetics Analysis using Maximum Likelihood, Evolutionary Distance, and Maximum Parsimony Methods. Mol Biol Evol 2011, 28:2731-2739.

21. Lole KS, Bollinger RC, Paranjape RS, Gadkari D, Kulkarni SS, Novak NG, Ingersoll R, Sheppard HW, Ray SC: Full length human immunodeficiency virus type 1 genomes from subtype C-infected seroconverters in India, with evidence of intersubtype recombination. J Virol 1999 73:152-160.

22. Bennett DE, Camacho RJ, Otelea D, Kuritzkes DR, Fleury H, Kiuchi M, Heneine W, Kantor R, Jordan MR, Schapiro JM, Vandamme AM, Sandstrom 
P, Boucher CA, van de Vijver D, Rhee SY, Liu TF, Pillay D, Shafer RW: Drug resistance mutations for surveillance of transmitted HIV-1 drug-resistance: 2009 update. PLOS ONE 2009, 4:e4724. doi:10.1371/journal. pone.0004724

23. Johnson VA, Calvez V, Gunthard HF, Paredes R, Pillay D, Shafer R, Wensing AM, Richman DD: 2011 update of the drug resistance mutations in HIV-1. Top Antivir Med 2011, 19:156-164.

24. Neogi U, Bontell I, Shet A, De Costa A, Gupta S, Diwan V, Laishram RS, Wanchu A, Ranga U, Banerjea AC, Sönnerborg A: Molecular epidemiology of HIV-1 subtypes in India: Origin and evolutionary history of the predominant subtype C. PLOS ONE 2012, 7(6):e39819.

25. Violari A, Cotton MF, Gibb DM, Babiker AG, Steyn J, Madhi SA, Jean-Philippe P, Mclntyre JA, CHER Study Team: Early antiretroviral therapy and mortality among HIV-infected infants. N Engl J Med 2008, 359:2233-2244

26. Donnell D, Baeten JM, Kiarie J, Thomas KK, Stevens W, Cohen CR, Mclntyre J, Lingappa JR, Celum C, Partners in Prevention HSV/HIV Transmission Study Team: Heterosexual HIV-1 transmission after initiation of antiretroviral therapy: a prospective cohort analysis. Lancet 2010, 375:2092-2098.

27. Soundararajan $L$, Karunaianandham $R$, Jauvin $V$, Schrive MH, Ramachandran R, Narayanan PR, Fleury HJ, Swaminathan S: Characterization of HIV-1 isolates from antiretroviral drug-naive children in southern India. AIDS Res Hum Retroviruses 2007, 23:1119-1126.

28. Sehgal S, Pasricha N, Singh S: High rate of mutation K103N causing resistance to nevirapine in Indian children with acquired immunodeficiency syndrome. Ind J Med Microbiol 2008, 26:372-374.

29. Neogi U, Shet A, Shamsundar R, Ekstrand ML: Selection of nonnucleoside reverse transcriptase inhibitor-associated mutations in HIV-1 subtype C: evidence of etravirine cross-resistance. AIDS 2011, 25:1123-1126.

30. Pedrosa C, Queiroz AT, Alcantara LC, Drexler JF, Diaz RS, Weyll N, Brites C: High prevalence of primary antiretroviral resistance among HIV-1 infected adults and children in Bahia, a northeast state of Brazil. $J$ Acquir immune Defic Syndr 2007, 45:251-253.

31. Charpentier C, Gody JC, Tisserand P, Matta M, Péré H, Fournier J, Mbitikon $\mathrm{O}$, Bélec L: Surveillance of antiretroviral drug resistance mutations in untreated young children living in the Central African Republic. Antivir Ther 2011, 16:1347-1350.

32. Arrive E, Newell ML, Ekouevi DK, Chaix ML, Thiebaut R, Masquelier B, Leroy V, Perre PV, Rouzioux C, Dabis F, Ghent Group on HIV in Women and Children: Prevalence of resistance to nevirapine in mothers and children after single-dose exposure to prevent vertical transmission of HIV-1: a meta-analysis. Int J Epidemiol 2007, 36:1009-1021.

33. De Mulder M, Yebra G, Martin L, Prieto L, Mellado MJ, Rojo P, MuñozFernández MÁ, Jiménez de Ory S, Ramos JT, Holguín A, Madrid cohort of HIV-infected children: Drug resistance prevalence and HIV-1 variant characterization in the naïve and pretreated HIV-1- infected paediatric population in Madrid, Spain. J Antimicrob Chemother 2011, 66:2362-2371.

34. van Zyl GU, Cotton MF, Claassen M, Abrahams C, Preiser W: Surveillance of transmitted resistance to antiretroviral drug classes among young children in the Western Cape Province of South Africa. Pediatr Infect Dis J 2010, 29:370-371.

35. Poon AFY, Aldous JL, Mathews WC, Kitahata M, Kahn JS, Saag MS, Rodríguez B, Boswell SL, Frost SD, Haubrich RH: Transmitted Drug Resistance in the CFAR Network of Integrated Clinical Systems Cohort: Prevalence and Effects on Pre-Therapy CD4 and Viral Load. PLOS ONE 2011, 6:e21189. doi:10.1371/journal.pone.0021189.

36. de Ronde A, van Dooren M, van Der Hoek L, Bouwhuis D, de Rooij E, van Gemen B, de Boer R, Goudsmit J: Establishment of new transmissible and drug-sensitive human immunodeficiency virus type 1 wild types due to transmission of nucleoside analogue-resistant virus. J Virol 2001, 75:595-602.

37. Garcia-Lerma JG, Nidtha S, Blumoff K, Weinstock H, Heneine W: Increased ability for selection of zidovudine resistance in a distinct class of wildtype HIV-1 from drug-naive persons. Proc Natl Acad Sci U S A 2001, 98:13907-13912

38. Sungkanuparph S, Kiertiburanakul S, Sukasem C, Chantratita W: Discrepancies between WHO 2009 and IAS-USA 2009 lists for determining the rate of transmitted HIV-1 drug resistance: a prospective study. J Acquir Immune Defic Syndr 2012, 59:e3-e5.
39. Guidelines for surveillance of HIV drug resistance. 2003, http://wwwn.cdc. gov/dls/ila/cd/who-afro/resisguide12_12.pdf.

40. Mellors JW, Munoz A, Giorgi JV, Margolick JB, Tassoni CJ, Gupta P, Kingsley LA, Todd JA, Saah AJ, Detels R, Phair JP, Rinaldo CR Jr: Plasma viral load and CD4+ lymphocytes as prognostic markers of HIV-1 infection. Ann Intern Med 1997, 126:946-954.

doi:10.1186/1471-2334-12-317

Cite this article as: Neogi et al:: High viremia and low level of transmitted drug resistance in anti-retroviral therapy-naïve perinatallyinfected children and adolescents with HIV-1 subtype $\mathrm{C}$ infection. BMC Infectious Diseases 2012 12:317.

\section{Submit your next manuscript to BioMed Central and take full advantage of:}

- Convenient online submission

- Thorough peer review

- No space constraints or color figure charges

- Immediate publication on acceptance

- Inclusion in PubMed, CAS, Scopus and Google Scholar

- Research which is freely available for redistribution 